\title{
Martin Scharfe, Bilder aus den Alpen. Eine andere
} Geschichte des Bergsteigens

Wien, Köln, Weimar : Böhlau Verlag, 2013, 216 p., 22,90€.

\section{Gaëlle Hallair}

\section{CpenEdition}

\section{Journals}

Édition électronique

URL : http://journals.openedition.org/ifha/8383

DOI : 10.4000/ifha.8383

ISSN : 2198-8943

Éditeur

IFRA - Institut franco-allemand (sciences historiques et sociales)

Référence électronique

Gaëlle Hallair, « Martin Scharfe, Bilder aus den Alpen. Eine andere Geschichte des Bergsteigens », Revue de l'IFHA [En ligne], Date de recension, mis en ligne le 01 janvier 2016, consulté le 22 septembre 2020. URL : http://journals.openedition.org/ifha/8383 ; DOI : https://doi.org/10.4000/ifha.8383

Ce document a été généré automatiquement le 22 septembre 2020.

(CIFHA 


\title{
Martin Scharfe, Bilder aus den Alpen. Eine andere Geschichte des Bergsteigens
}

Wien, Köln, Weimar : Böhlau Verlag, 2013, 216 p., 22,90€.

\author{
Gaëlle Hallair
}

1 L'ouvrage, dédié à l'histoire de l'alpinisme, valorise les fonds iconographiques de deux musées d'associations alpines, l'un en Autriche à Innsbruck et l'autre en Allemagne à Munich.

2 Ces fonds sont constitués d'images de natures variées s'échelonnant du XVIII ${ }^{\mathrm{e}}$ au XXI siècle. Celles-ci présentent au premier abord un intérêt essentiellement topographique. Mais l'auteur va plus loin et analyse le fonds sous l'angle historique en insistant sur le quotidien de l'alpinisme et les conditions socio-culturelles de la pratique de l'alpinisme. A partir d'un corpus de 6500 images, l'auteur a choisi d'éditer 66 images de natures variées: gravure, lithographie, peinture, aquarelle, fusain, dessin, caricature, etc. Répétant le même type de dispositif tout au long de l'ouvrage, l'auteur présente sur une à deux double-page(s) une image, ainsi qu'un détail et un court texte de présentation de ladite image.

En éditant ces sources iconographiques, l'auteur choisit une démarche analytique mettant l'accent sur 66 éléments selon une démarche que nous pourrions volontiers rattacher au Practical turn. Le Practical turn s'intéresse aux processus de construction et à la dimension pratique d'une thématique d'histoire des sciences. Cette démarche insiste notamment sur des objets particuliers (le bâton d'alpiniste, les chaussures de marche, le sac à dos, la hutte, le glacier), des personnes au statut le plus souvent reconnaissable grâce à leur vêtement (un chasseur, un guide, un homme aisé de la ville), des lieux privilégiés (ici la haute montagne magnifiée ou parfois anthropisée), des moments privilégiés (le départ, la pause, un moment dangereux, un passage risqué, l'accident, la religion, la méditation, la spiritualité), des conditions socio-culturelles précises (en particulier la hiérarchisation entre le guide rural, montagnard qui se fait payer et les messieurs de la ville de condition privilégiée, en vêtements de ville).

Pour ce travail d'édition de sources et de commentaires, l'ouvrage est organisé en 66 entrées correspondant aux 66 clichés retenus; chacun d'entre eux exprime un aspect 
de l'histoire de l'alpinisme. Ce travail précis et soigné est précédé d'une courte introduction explicitant l'objectif de l'ouvrage. Le livre s'achève sur un registre à triple entrée fort utile : par lieu, par personne et par thème.

5 Ce précieux travail d'édition de sources est fort utile pour nourrir ensuite une réflexion plus théorique sur l'image et les corpus iconographiques, leur mise en valeur et aussi leur signification pour l'histoire des sciences et la construction des savoirs. Cet ouvrage encourage à des rapprochements avec les travaux de Horst Bredekamp sur le rôle de l'image dans la constitution des savoirs.

6 Vous trouverez la table des matières ici : http://d-nb.info/102863756x/04.

INDEX

Index chronologique : Époque contemporaine, Période moderne

Thèmes : Sources, Histoire des sciences, Histoire des milieux naturels

\section{AUTEUR}

GAËLLE HALLAIR

CNRS-UMR 8504 Géographie-Cités, Paris 